\title{
Research on the Method of Improving the Quality of Classroom Teaching in Private Colleges
}

\author{
Chen Ruihua \\ Quanzhou Institute of Information Engineering, Quanzhou, Fujian, China \\ Corresponding author. Email:244473332@qq.com

\begin{abstract}
Classroom teaching quality is effected by various factors in private colleges, such as students are loss of learning consciousness, teachers are lack of necessary expertise and responsibility, or teachers can't maintain discipline in classroom. This paper takes the classroom teaching of "Marketing"as an example, and finds that classroom teaching should not only pay attention to teaching methods and make full preparations before and after teaching, but also adhere to the principle of "student-centered", use innovative teaching methods to mobilize the enthusiasm of students, establish and improve communication and feedback mechanisms, and establish a learning community, so as to create a harmonious classroom and high quality of classroom teaching.
\end{abstract} \\ Keywords: private college, quality of classroom teaching, marketing
}

\section{提高民办高校课堂教学质量的方法探究}

\author{
陈瑞华
}

\author{
泉州信息工程学院 \\ 电子邮箱244473332@qq. com
}

\begin{abstract}
摘要
民办高校课堂教学质量受诸多因素影响, 如学生学习意识不强、教师专业教学水平不强、责任心不够、 课堂秩序欠佳等问题。本文以《市场营销学》课程的课堂教学为例, 对民办高校课堂教学质量进行分 析, 发现课堂教学不仅要讲究教学方法、充分做好教学前后的准备工作, 还要秉承 “生本主义” 原则, 使用创新教学方式来调动学生积极性, 建立健全沟通和反馈机制, 建立学习共同体, 才能营造和谐课 堂、提高课堂教学质量。
\end{abstract}

关键词: 民办高校; 课堂教学质量; 《市场营销学》

\section{1. 引言}

民办高校是指国家机构以外的个人或者社会组织, 利用非国家的财政性经费, 依法面向社会举办的学校或 者其他形式的教育机构, 办学层次一般分为本科和专科 [1]。高校课堂教学一直以来是高校的重心工作之一, 尤其 是在当今高等教育高度重视本科教学, 强调 “以本为本” 的背景下, 可以说课堂教学的质量与学生成长密切相关, 直接关系到学生对学校的评价与认同。现今, 00 后的大 学生接受新观念、新事物容易, 独立性强, 思想活跃。 传统的 “教师中心” 课堂教学范式已经过时, 因此探索 新的提高课堂教学质量方法刻不容缓。民办高校由于自
身形式的特殊性导致其教师队伍的稳定性不够。且为 节省教学资源每个自然班级的人数都比较多, 有的课 程甚至还两三个班级合班上课。对提升课堂教学质量, 实现 “以生为本” 的教学范式增加了阻力。

\section{2. 民办高校课堂教学存在的不足}

\section{1学生的学习意识不强, 缺乏学习的动力}

近年, 我国高等教育已经进入大众化时代, 随着 高校数量的增多、招生比例不断扩大，传统的高校选 择学生的模式越来越受到挑战。民办本科院校的生源 质量普遍不高, 学生学习意识不强, 学习目标不明确, 缺乏学习的动力。这是导致当前民办高校课堂教学质 量低的主要原因之一。 
创新, 如《市场营销学》课程里面的消费者购买行为

\section{2教师专业能力不高、责任心不强}

民办高校受资金限制, 教师数量有限, 教师梯队不 够合理, 很多刚毕业的年轻教师并非师范学院校出身, 缺少教书育人的高尚品德。且年轻教师 “身兼数职”, 除上课外, 还要兼职带班、带专业社团、指导学生竞赛 等, 繁重的教科研任务, 不利于教师教学经验的积累和 总结。加之部分教师责任心不够强, 对课堂教学质量不 够重视, 上课只管灌输式的把知识 “灌” 给学生, 不管 理学生是否能够吸收, 对于课堂秩序更是不予管理, 课 堂教学效果不佳。

\section{3教师无法与学生形成 “对话”}

现今的大学生多数是 00 后, 他们个体意识和个人主 义较强, 追求平等、互动和个性, 传统的 “讲授-接受” 的课堂教学模式已经不适用。而民办高校教师的教学工 作量大, 课后任务繁重, 和学生在一起的交流学习的时 间少, 沟通不够。教学过程中无法与学生行程 “对话”, 导致课堂教学过程中频频出现 “你做你的、我做我的” 的筳尤局面, 大大影响了课堂教学质量的提高。

\section{3. 提升课堂教学质量的教学思路一一以《市场 营销学》课程教学为例}

以往, 民办高校课堂教学的工作, 主要是 “教师中 心” 的教学范式, 只一味强调教师对学生的研究。研究 他们的各种特点、优点、缺点等, 之后按照教师设定的 教学目标, 试图通过各种途径, 例如教育、引导、灌输 等, 来 “改造” 学生。在这个过程中, 教师几乎不研究 自己, 或者研究甚少, 因为传统的课堂教学中, 教师既 是 “主导” 又是 “主体”。然后随着社会的发展, 此种 教学范式已经不适应新时期的高校课堂了。因此, 笔者 在进行《市场营销学》这门课程的教学过程中尝试探索 使用, 教师、学生双主体的课堂教学范式。

\section{1 充足的课前准备}

《市场营销学》课程是一门建立在经济科学、行为 科学和现代管理理论基础之上的综合应用科学。它不仅 是当代企业在迅速变化的市场环境和日趋激烈竞争中求 生存、求发展的管理利器, 而且已逐渐成为新时代青年 的一种核心思维方式。要提高课堂教学质量, 教师在上 课前一定要设计好既符合课程大纲要求又适合新时期大 学生的特点的教学目标和课程设计。要提高课堂教学质 量, 不是教师单方面努力就能实现的, 学生是课堂教学 最直接的感受者, 他们的评价也就最真实、最直接。只 有让学生参与到课堂中, 多征求他们的意见, 倾听他们 的想法, 才能师生共同把课堂教学的质量提上去。因此, 教师必须要进行充分的课程分析, 并在教学设计上进行
分析, 在设计课程的时候, 可以结合生活实际, 通过 情景互动, 让学生融入课堂。

课前准备具体包括以下几点:

\section{1.1 制定学生的习作计划}

《市场营销学》作为经济管理学院各专业的专业 基础课之一，在专业人才培养体系中起到承上启下的 作用, 即学习该课程的学习已有一定的经济学和管理 学的基础, 学完这门课程可为后续营销类的课程奠定 一个基础。清楚了该课程在人才培养中起到的作用后, 就能结合学生特点制定出整个学习的习作计划。

\section{1.2 做好充足的开课前准备}

在课程开始前, 利用超星学习通, 建立课程, 导 入班级名单, 给学生创建提前学习的平台。从而让学 生了解要讲的内容, 或者给学生布置一定的任务, 让 学生分组讨论, 不同的学习小组通过网络、书籍等工 具, 收集有关市场营销的相关知识, 内容可以是文字、 图片和一些相关的视频。[3]

\section{1.3 充分备课}

充分的备课是上好课的前提。教师要对教材进行 合理的处理, 从学生出发。以学生发展为主并要始终 把学生放在心里, 也就是说备课必须要备学生。备课 不仅要备教材、还要备学生、备老师课, 比如一堂课 应分为几部分, 怎样与学生进行交流等等就应是教师 所需要考虑的。

\section{2 课中实施}

教师上课不仅要充满活力, 举止端庄, 板书要正 确、清楚、工整, 还要学会与学生 “对话”。对话意 味着平等、协商, 双方可以共同沟通想法、观点, 能 够使不同的意见有得以表达的地方, 把矛盾降低最小 点, 通过对话能够达成共识。在对话中, 教师和学生 能够表达不同的看法, 找到共同的地方, 达成默契, 使双方关系更加和谐。

\subsection{1 上好第一堂课}

新学期的第一堂课上得好不好, 可能直接影响到 学生对课程的喜恶, 对后面的课程教学起到极为重要 的作用。所以教师要善用心理学中的首因效应, 先用 幽默风趣的方式进行一次全面的说课, 让学生明白《市 场营销学》这门课程的内容框架, 为什么要学、如何 


\section{3. 3 对 “教学设计” 的反思}

务必在第一堂课跟学生说明清楚, 让学生变成学习的主 体, 知道这门课程在学习的过程中它们需要做什么、教 师是如何考核他们的。

\subsection{2 创新课堂教学}

现今, 在组织课堂教学时, 如果还是采用传统的讲 授和灌输的方式, 已经不能完成适用于新时期的高校课 堂了。课堂教学应该转变为由教师和学生、学生和学生 之间共同构成的一个学习共同体, 在这样的一个共同体 中, 教师要善于巧妙运用各种技巧使教师与学生、学生 与学生之间构建一种平等、合作、信任的关系, 在良好 的氛围下, 激励和引导学生学习和思考, 师生共同完成 课堂教学任务。在教授《市场营销学》这门课时, 笔者 多种教学方法相结合。在教学的过程中讲授法、案例分 析法、分组讨论法、景模拟法等多法并用。

在民办高校中普遍存在的一个问题就是自然班级的 人数过多, 教师在上课的过程中难以顾及到每一位同学。 因此笔者在教授《市场营销学》这门课程时, 先把班级 同学按随机原则分成 6 至 7 位同学一组, 进行分组安排。 一来方便完成课堂讨论, 二来方便组员间相互监督、互 相学习。通过分组模式, 教师上课的关注点更加密集。 小组之间给他们设立竞争机制, 组员的团结协作精神在 课堂上就能很好的体现出来。这样的教学组织方式适用 与追求平等、互动和个性的新时期的大学生, 但要求教 师要放低姿态, 更多从学生的角度思考如何教学, 如何 使他们更能接受课堂讲授的知识内容, 更好地提高课堂 教学的质量。

\section{3 课后反思}

课后反思即教后所思, 认真总结思考教学过程中的 得与失。对教学过程中的得失进行必要的归纳, 进一步 改善教学方法, 创新教学思维。

需要反思的内容:

\section{3. 1 对教学 “目标” 的反思}

反思本课教学目标是否达到、教学过程中是否进行 互动、教学气氛是否活跃、教学效果如何、课堂纪律是 否良好等等。

\section{3.2 对学生 “学” 的反思}

学生是学习的主体, 教师应积极引导学生一起参与 讨论课堂问题, 学生角度看的问题在课堂教学过程中会 有一些闪光点, 教师要肯定学生的见解并进行思路的拓 展, 记录下问题讨论过程中学生的创新点。
上完一堂课, 通过对教学方法、教学模式、教学 效果等方面的分析, 再次做出教学设计, 提升自己的 教学水平。

在以上三点反思的基础上, 还要及时构建学生教 学反馈和课后师生交流的渠道。了解学生对教师课堂 教学质量的评价以及意见, 倾听他们的想法, 并做到 及时互动和反馈。良好、理性、畅通、及时的反馈机 制和沟通、互动渠道, 有助于构建具有活力、张力、 和谐的师生关系, 增强师生的信任与尊重。比如《市 场营销学》课程, 笔者建立了一个课后学习交流 QQ 群、 学习通课程交流群, 通过这些渠道, 教师能在对学生 进行答疑解问, 同时还能在群里得到学生的教学反馈, 有利于进一步提高教学的有效性。

\section{4. 总结}

当前, 高等教育已经进入大众化时代, 传统的 “命 令-服从” 或 “讲授-接受” 的课堂教学模式难以成效, 教师在课堂教学中要遵守平等的原则, 而非命令-服从 的方式与学生沟通交流, 要帮助学生提高沟通交流的 能力, 使学生能够与教师互动和合作, 表达自己, 提 高学习的积极性和有效性。德国著名哲学家哈贝马斯 “认为道德律行为是人与人之间、主体与主体之间的 相互交往, 只有通过他们之间的交往、交谈、对话, 才能达成共识, 达成具有普遍性的道德律。” ${ }^{[4]}$ 要提 高民办高等院校的课堂教学质量, 要求教师不仅要把 自己看成是主体, 也要把学生看成是主体, 同时还要 让学生也要把自己看成主体, 在课堂教学过程中, 师 生双方要加强互动、沟通和协调, 努力达成和谐状态。

\section{REFERENCES}

[1] Zhao Rui. A study on the Teaching Quality System in Privately-run Colleges in China [D]. Northwest University of Agriculture and Forestry Science and Technology,2014.

[2] Ma Lin, Yan Zhen, Chai Guojun. Practical exploration of graduation design of marketing [J]. Journal of Inner Mongolia University of Finance and Economics (Comprehensive Edition), 2004 (01): 29-31

[3] Wang Bo. Research on methods to improve classroom teaching quality in Vocational Colleges under the current economy -- Analysis of teaching practice based on introduction to e-commerce [J]. Modern marketing (Chuangfu information edition), 2018 (12): 110

[4] Shiying Zhang, Introduction to Philosophy, Peking University Press,2006: pp.246 
[5] Chen Ruihua. Reform and exploration of marketing teaching mode based on training for the ability of students [J]. Economic and Trade Practice, 2016(14): 235-236. 